\title{
A proximity-dependent assay for specific RNA-protein interactions in intact cells
}

\author{
WEI ZHANG, ${ }^{1,6,7}$ MINGYI XIE, ${ }^{2,3,6,8}$ MEI-DI SHU, ${ }^{2,3}$ JOAN A. STEITZ, ${ }^{2,3,4}$ and DANIEL DIMAIO ${ }^{1,3,4,5}$ \\ ${ }^{1}$ Department of Genetics, Yale School of Medicine, New Haven, Connecticut 06520-8005, USA \\ ${ }^{2}$ Howard Hughes Medical Institute, Yale University School of Medicine, New Haven, Connecticut 06520-208024, USA \\ ${ }^{3}$ Department of Molecular Biophysics and Biochemistry, Yale University School of Medicine, New Haven, Connecticut 06520-208024, USA \\ ${ }^{4}$ Yale Cancer Center, New Haven, Connecticut 06520-8028, USA \\ ${ }^{5}$ Department of Therapeutic Radiology, Yale School of Medicine, New Haven, Connecticut 06520-208040, USA
}

\begin{abstract}
The proximity ligation assay (PLA) is an immune staining method that detects protein-protein interactions in fixed cells. We describe here RNA-PLA, a simple adaptation of this technology that allows the detection of specific RNA-protein interactions in fixed cells by using a DNA oligonucleotide that hybridizes to a target RNA in combination with an antibody that recognizes the protein bound to the target RNA. Stable and transient RNA-protein interactions can be readily detected by generation of a fluorescent signal in discrete compartments in intact fixed cells with high specificity. We demonstrate that this approach requires the colocalization of the binding protein and its RNA target in the same cellular compartment, use of an oligonucleotide complementary to the target RNA, and the presence of a binding site for the protein in the target RNA.
\end{abstract}

Keywords: PLA; RNA-protein complex; small nuclear RNA; RNP; gene expression

\section{INTRODUCTION}

RNA-binding proteins associate with RNA molecules in cells to form ribonucleoprotein (RNP) complexes that regulate the post-transcriptional activity of RNAs by affecting their processing, subcellular localization, translation, or stability (Lunde et al. 2007; Glisovic et al. 2008). The study of RNA-protein interactions has primarily relied on the use of biochemical techniques, such as RNA electrophoretic mobility shift assays, pull-down assays, and RNase $\mathrm{H}$ assays (Zurla et al. 2016). Although powerful methods have been developed to visualize individual engineered RNAs in cells (Raj et al. 2008; Paige et al. 2011; Strack and Jaffrey 2015), it is difficult to detect and localize specific RNA-protein complexes within cells. Sequential detection of RNA and protein by fluorescence in situ hybridization (FISH) and immunofluorescence can be used for this purpose, but this method is time consuming and technically challenging. In addition, colocalization analyses are sometimes compromised by the relative signal-to-noise ratio and relatively low resolution of the images.

\footnotetext{
${ }^{6}$ Co-senior authors.

${ }^{7}$ Present address: Etubics, Seattle, WA 98119, USA

${ }^{8}$ Present address: Department of Biochemistry and Molecular Biology, UF Health Cancer Center, University of Florida, Gainesville, FL 32610, USA

Corresponding author: daniel.dimaio@yale.edu

Article published online ahead of print. Article and publication date are at http://www.rnajournal.org/cgi/doi/10.1261/rna.058248.116.
}

The proximity ligation assay (PLA) is a sensitive tool for examining protein-protein interactions in cells (Soderberg et al. 2006). In PLA, a pair of interacting proteins of interest are recognized by different primary antibodies and specific corresponding secondary antibody probes conjugated to unique short DNA oligonucleotides. If the target proteins are in close proximity (nominally within $40 \mathrm{~nm}$ ), the oligonucleotides can hybridize to two additional oligonucleotides, bridging them to form a DNA circle. Following ligation and rolling-circle amplification (RCA) using one of the antibodyconjugated oligonucleotides as a primer, hybridization of a fluorescently labeled oligonucleotide probe to the amplification product generates punctate fluorescent signals as an indication of protein pairs in close proximity.

Modified PLA protocols have been developed to study RNA-protein interactions in cells (Jung et al. 2013a,b; Weibrecht et al. 2013). However, these methods are relatively complex and involve manipulations such as localized cDNA synthesis using a primer containing locked nucleic acidmodified bases followed by visualization with padlocked probes and target-primed amplification. Alternatively, the construction of peptide- and dye-conjugated chemically modified RNA-DNA oligonucleotide chimeras and their

(c) 2016 Zhang et al. This article is distributed exclusively by the RNA Society for the first 12 months after the full-issue publication date (see http://rnajournal.cshlp.org/site/misc/terms.xhtml). After 12 months, it is available under a Creative Commons License (Attribution-NonCommercial 4.0 International), as described at http://creativecommons.org/licenses/by-nc/4.0/. 
delivery into cells by streptolysin O-mediated permeabilization can be used to detect RNA-protein interactions in cells.

Here, we report a simple PLA method that can detect interactions between an unmodified endogenous or exogenous RNA and a binding protein in situ in fixed cells. In this RNA-PLA protocol, one of the primary antibody/probe pairs in standard PLA is replaced by a DNA oligonucleotide containing a 40-50 nucleotide (nt) segment complementary to the RNA of interest, 20-35 adenylates as a linker segment, and a common 25-nt segment that serves as one of the PLA hybridization/ligation arms (PLUS probe) (Fig. 1). A protein bound to the targeted RNA is recognized by a primary antibody and a secondary antibody probe conjugated to the other PLA hybridization/ligation arm (MINUS probe). When the protein is bound to the target RNA, the two probes will hybridize to two other oligonucleotides that form a closed DNA circle after ligation. The PLUS probe then serves as a primer for RCA as in classic PLA, and the signal is observed as spots after hybridization with a fluorescently labeled oligonucleotide. In an earlier report, we used this method to detect a transient interaction between a viral transcript and its cellular processing enzyme (Xie et al. 2015). Here, we provide further details and documentation that this method can be used to detect interactions between native viral and cellular small nuclear RNAs (snRNAs) as well as mRNAs and their corresponding binding proteins at the single-cell and subcellular level.

\section{RESULTS}

\section{Detection of complexes between proteins and small nuclear RNAs}

We first assessed the RNA-PLA method by testing known nuclear RNA-protein interacting pairs. U1 and U2 snRNAs associate with Sm proteins to form the small nuclear ribonucleoproteins (snRNPs) of the spliceosome and reside primarily within the nucleus (Seraphin 1995). To determine whether RNA-PLA can detect these interactions, HeLa cells were fixed, permeabilized, and incubated with anti-Sm antibody (and a corresponding commercially available oligonucleotide-conjugated secondary antibody probe) and an RNA-PLA oligonucleotide probe containing a $5^{\prime}$ segment sense or antisense to U1 or U2 RNA. After the samples were processed for PLA, specific green fluorescent nuclear signals were detected in samples incubated with the oligonucleotides antisense U1 or U2 RNA, but not with the sense oligonucleotides (Fig. 2A,B). These data show that RNA-PLA detects endogenous stable nuclear RNA-protein interactions.

To further explore the specificity of RNA-PLA, we detected the association of the Lupus autoantigen (La) protein with Epstein-Barr virus (EBV)-encoded RNA 2 (EBER2), a small noncoding RNA that is abundantly expressed in the nucleus of EBV-infected cells (Lerner et al. 1981; Glickman et al. 1988). La is a nuclear protein that associates with the $3^{\prime}$ ends of RNA polymerase III transcripts to promote their maturation (Wolin and Cedervall 2002; Fok et al. 2006). EBER2 interacts with La protein to form RNP complexes that bind to the terminal repeat sequences of the EBV genome (Lerner et al. 1981; Wolin and Cedervall 2002; Lee et al. 2015). $\mathrm{BJAB}$ is an EBV-negative human Burkitt lymphoma B-cell line and $\mathrm{BJAB}-\mathrm{B} 1$ is a clonal $\mathrm{BJ} A \mathrm{~B}$ derivative harboring a latent EBV genome that expresses EBER2 (Fresen and zur Hausen 1976). We performed RNA-PLA on both cell lines using a primary antibody against La protein and an RNAPLA oligonucleotide probe for EBER2. RNA-PLA signals were observed in the EBV-positive BJAB-B1 cells when the antisense oligonucleotide, but not the sense oligonucleotide, was used (Fig. 2C). As expected, the signals were present

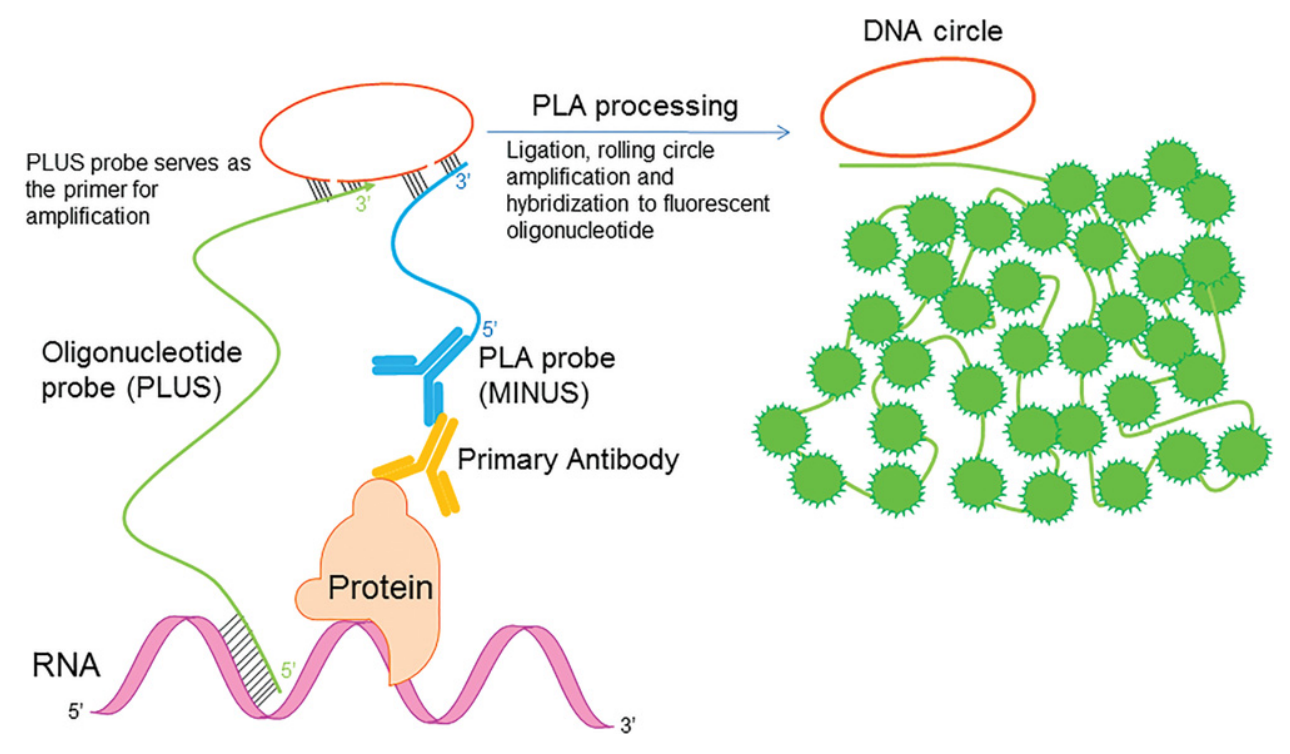

FIGURE 1. Schematic of RNA-PLA. See text for details. 


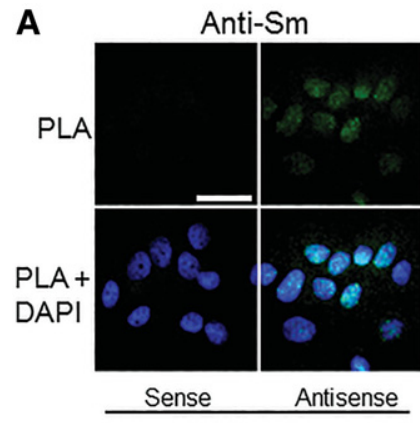

U1 probe

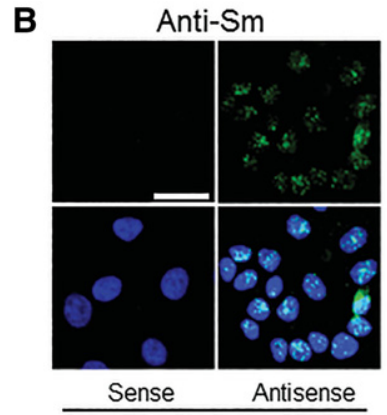

U2 probe

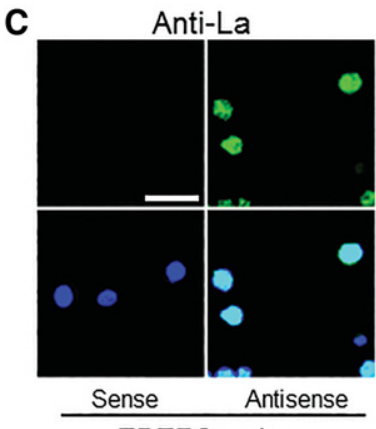

EBER2 probe

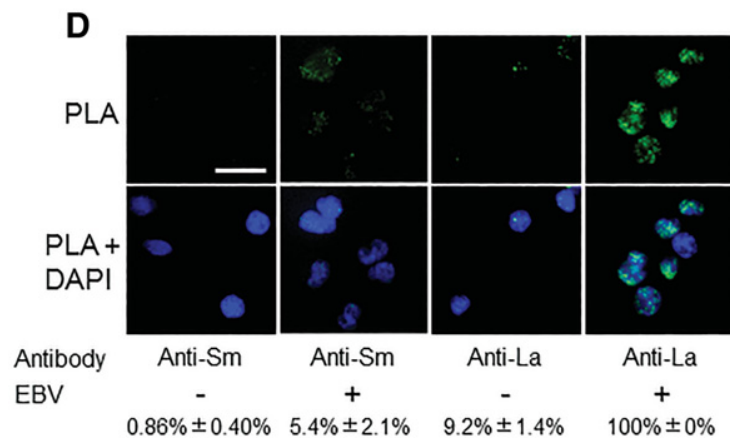

FIGURE 2. Specific detection of stable nuclear RNA-protein interactions by RNA-PLA. HeLa cells were fixed, permeabilized, and incubated with anti-Sm antibody and an oligonucleotide sense or antisense to U1 (A) or U2 (B) RNA. PLA was then performed to detect the interaction of Sm protein and the U RNA (green); nuclei were stained with DAPI (blue). In each column, a confocal image of the same Z-plane is displayed for the PLA signal (top) and the merged signal with DAPI (bottom). Representative results of three independent experiments are shown. Scale bar, $20 \mu \mathrm{m}$. $(C)$ As described in panels $A$ and $B$, RNA-PLA was used to detect the interaction of La protein and EBER2 in BJAB-B1 (EBV+) cells by using anti-La antibody and an oligonucleotide sense or antisense to EBER2. (D) BJAB (EBV-) and BJAB-B1 (EBV+) cells were fixed, permeabilized, and incubated with the antisense oligonucleotide to EBER2 and the anti-La or the anti-Sm antibody. PLA was then performed as described above. A representative result of three independent experiments is shown. The total RNA-PLA fluorescence intensity per cell in each sample (minimum 150 cells each condition) was measured by Blobfinder software. The numbers at the bottom show the average results ( \pm standard error of the mean [SEM]) for three experiments relative to the $\mathrm{La} / \mathrm{EBER} 2$ signal in $\mathrm{BJAB}-\mathrm{B} 1$ cells.

exclusively in the nucleus, where La and EBER2 localize. In contrast, little signal was observed when La/EBER2 RNAPLA was performed in BJAB cells lacking EBV, or in EBV-infected BJAB-B1 cells if the anti-La antibody was replaced with an anti-Sm antibody (Fig. 2D). Although Sm protein is abundant in nucleus, it does not bind EBER2, which lacks an Sm protein-binding site (Moss et al. 2014). Thus, a robust RNAPLA signal requires coexpression of the interacting protein and its target RNA, as well as the use of an antisense RNAPLA oligonucleotide probe.

\section{Detection of complexes between protein and mRNA in discrete cellular compartments}

The RNA-PLA assay can also be used to localize mRNA-protein interactions in various cell compartments. HuR (Human antigen $\mathrm{R}$ ) is an RNA-binding protein that interacts with specific AU- or U-rich elements (AREs) in certain mRNAs (Darnell 1996; Gallouzi et al. 2000; Lopez de Silanes et al. 2004). This interaction is important for regulating mRNA stability and translational efficiency (Dai et al. 2012). HuR is predominantly localized in the nucleus, but treatment with the transcription inhibitor actinomycin $\mathrm{D}(\mathrm{ActD})$ causes translocation of HuR into the cytoplasm (Supplemental Fig. S1; Gallouzi et al. 2000; Lopez de Silanes et al. 2004). Cytoplasmic HuR can bind to AREs in the $3^{\prime}$-untranslated region ( $3^{\prime}$ UTR) of mRNAs, affecting mRNA stability (Dormoy-Raclet et al. 2007).

We used RNA-PLA to investigate whether HuR interacts with a specific mRNA in different subcellular compartments. We chose to investigate $\beta$-actin mRNA, which binds to HuR via a $3^{\prime}$ U-rich sequence (Lopez de Silanes et al. 2004; Dormoy-Raclet et al. 2007; Jung et al. 2013b). HeLa cells were treated with $5 \mu \mathrm{g} / \mathrm{mL}$ ActD or vehicle control for $1 \mathrm{~h}$, fixed and processed for RNA-PLA using a primary antibody recognizing $\mathrm{HuR}$ and a $\beta$-actin mRNA-specific RNA-PLA oligonucleotide probe. In cells without ActD treatment, we observed weak PLA signals exclusively in the nucleus when the antisense probe was used and no signals with the sense probe, suggesting that $\mathrm{HuR}$ interacts with the low levels of $\beta$-actin transcripts in the nucleus (Fig. 3A, left two panels). As shown in the right two panels of Figure $3 \mathrm{~A}$, ActD treatment results in the generation of a significant cytoplasmic RNA-PLA signal with the antisense, but not the sense $\beta$-actin oligonucleotide probe, due to HuR translocation to the cytoplasm where it interacts with the much more abundant cytoplasmic $\beta$-actin 
A

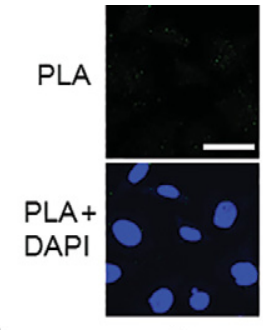

ActD

B-Actin MRNA probe

Sense

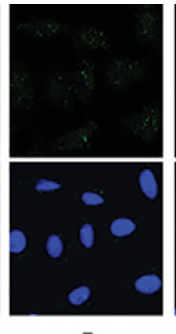

$0.64 \% \pm 0.39 \%$

Antisense

$17 \% \pm 3.3 \%$

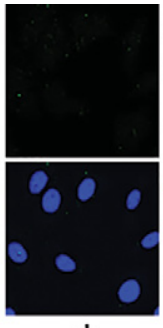

$+$

Sense

$9.7 \% \pm 2.7 \%$

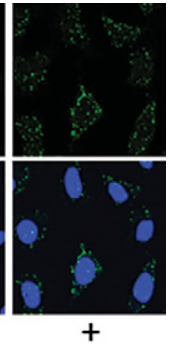

Antisense $100 \% \pm 0 \%$
B
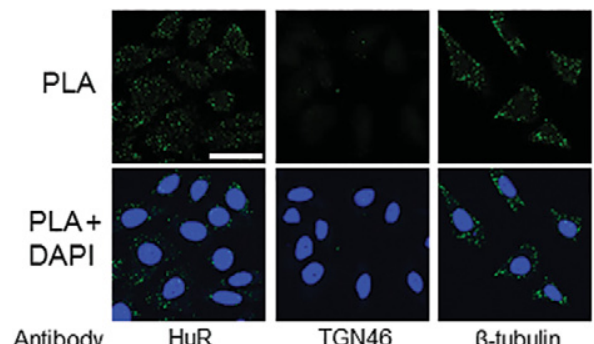

FIGURE 3. Detection of mRNA-protein interactions in subcellular compartments by RNA-PLA. (A) HeLa cells were treated with ActD $(+)$ or vehicle control $(-)$ for $1 \mathrm{~h}$, fixed, permeabilized, and incubated with an anti-HuR antibody and an oligonucleotide sense or antisense to $\beta$-actin mRNA. PLA and confocal microcopy were performed as described in Materials and Methods and displayed as in Figure 2. The PLA signal was quantified and is shown as the average results $( \pm$ SEM) for three experiments relative to the HuR/ $\beta$-actin mRNA signal with the antisense probe in the ActD-treated cells. $(B)$ HeLa cells were treated with ActD for $1 \mathrm{~h}$, fixed and processed for PLA with an oligonucleotide that is antisense to $\beta$-actin mRNA and anti-HuR antibody, anti-TGN46 antibody, or anti- $\beta$-tubulin antibody, as indicated. PLA and confocal microcopy were then performed as described above.

mRNA. FISH confirmed that only the antisense RNA-PLA $\beta$ actin probe detects cytoplasmic $\beta$-actin mRNA (Supplemental Fig. S2). These data demonstrate that the RNA-PLA assay can be used to track mRNA-protein interactions spatially.

We carried out additional specificity controls in ActDtreated cells to confirm that HuR specifically recognizes $\beta$-actin mRNA. RNA-PLA failed to generate a robust PLA signal for the association of $\beta$-actin mRNA with TGN46 (an irrelevant trans-Golgi network marker) (Fig. 3B). In contrast, RNA-PLA showed that $\beta$-actin mRNA strongly associates with $\beta$-tubulin in the cytoplasm, consistent with previous reports that the cytoskeleton is involved in $\beta$-actin mRNA transport (Hesketh and Pryme 1991; Condeelis and Singer 2005; Lifland et al. 2011; Jung et al. 2013a).

\section{RNA-PLA detection requires a binding site for the protein partner on the target RNA}

Previous biochemical studies showed that the insertion of the ARE sequence from c-fos or GM-CSF (granulocyte-macrophage colony-stimulating factor) into the $3^{\prime}$ UTR of rabbit $\beta$-globin mRNA allows HuR binding (Fan et al. 1997), result- ing in rapid degradation of the mRNA. To confirm that ARE sequences are required for the interaction between $\mathrm{HuR}$ and target mRNA detected by RNA-PLA, we tested the association of HuR and native rabbit $\beta$-globin mRNA, which lacks an endogenous ARE, or rabbit $\beta$-globin mRNA containing an exogenous ARE (Fig. 4A; Fan et al. 1997). HeLa cells were transfected with $\mathrm{pBBB}$ expressing rabbit $\beta$-globin mRNA or with plasmids expressing $\beta$-globin mRNA containing a foreign ARE, treated with $5 \mu \mathrm{g} / \mathrm{mL}$ ActD for $1 \mathrm{~h}$, fixed and processed for RNA-PLA using anti-HuR antibody and an RNA-PLA oligonucleotide probe specific for rabbit $\beta$-globin mRNA. In cells transfected with $\mathrm{pBBB}$, which expresses $\beta$-globin mRNA lacking an ARE, minimal RNA-PLA signal was detected. In contrast, we observed strong RNA-PLA signals in samples transfected with a $\beta$-globin construct containing a $c$-fos or GM-CSF ARE when the antisense but not the sense oligonucleotide probe was used (Fig. 4B). Thus, the absence of the binding site on the RNA substantially reduces the signal, showing that the target protein and RNA must physically interact for RNA-PLA to generate a robust signal. Because insertion of an ARE into $\beta$-globin mRNA greatly reduces its stability (Fan et al. 1997), the ARE-containing RNAs are less abundant than control $\beta$-globin mRNA in transfected cells (Fig. 4C), even though a higher amount of DNA was used for transfection of the GM-CSF and c-fos constructs (compared to $\mathrm{pBBB}$ ) in an attempt to achieve higher $\beta$-globin mRNA expression levels in cells expressing these transcripts. The much higher RNA-PLA signals in cells receiving the ARE-containing transcripts, despite the lower absolute $\beta$-globin mRNA levels in these cells, further demonstrates the sensitivity and specificity of this assay.

\section{DISCUSSION}

In this study, we modified the PLA procedure to detect the specific association of RNAs with their binding proteins inside single cells. We detected a strong RNA-PLA signal indicative of stable nuclear complexes between two U-class cellular snRNAs and the Sm protein, and between viral EBER2 RNA and the La protein. As expected, RNA-PLA probes for an interaction between EBER2 and Sm generated only a weak RNA-PLA signal, even though these molecules are both abundantly expressed in the nucleus. The weak signal generated by this probe set presumably represents lowlevel background staining, which is in general $<10 \%$ as intense as an authentic RNA-PLA signal generated by complex formation. We also showed that we can detect specific interactions between an RNA binding protein and its target mRNA in discrete intracellular compartments and that a strong RNA-PLA signal requires a binding site for the protein on the target mRNA. In previously published work, we used RNA-PLA to detect a transient interaction in 293T cell nuclei between an unusual bipartite Herpesvirus saimiri (HVS) primary-microRNA (pri-miRNA) and the Int9 subunit of the Integrator complex, which processes this RNA (Xie et al. 
A

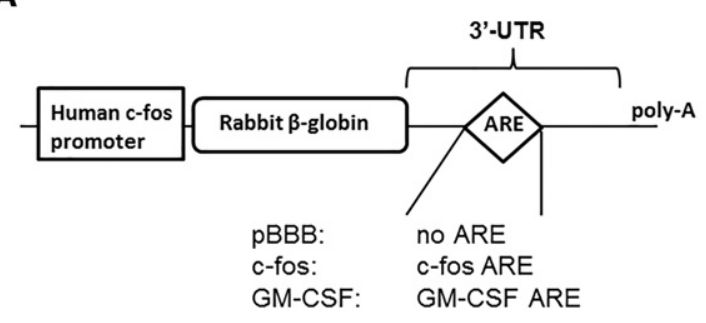

B

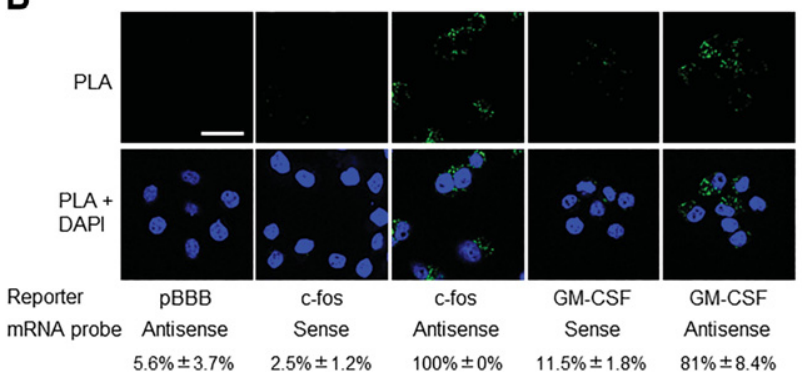

C


FIGURE 4. RNA-PLA detection requires a protein-binding site on the RNA. (A) Schematic diagram of the $\beta$-globin reporter constructs. pBBB does not contain an ARE. The GM-CSF and c-fos constructs contain the c-fos and GM-CSF AREs, respectively, inserted into the $3^{\prime}$ UTR of the $\beta$-globin reporter plasmid. $(B)$ HeLa cells were transfected with the $\beta$-globin constructs, treated with ActD, fixed and processed for PLA using anti-HuR antibody and an oligonucleotide antisense or sense to $\beta$-globin mRNA, as indicated. PLA and confocal microcopy were then performed as described above. The total PLA fluorescence intensity per cell in each sample (minimum 150 cells each condition) was measured using the Blobfinder software and is shown as the average results $( \pm \mathrm{SEM})$ for three experiments relative to the signal in the sample transfected with the c-fos ARE/ $\beta$-globin construct and processed for RNA-PLA with the antisense probe. Results of a representative experiment are shown. Similar results were obtained in three independent experiments. $(C)$ Northern blot analysis of $\beta$-globin RNA containing or lacking an ARE. Total RNA was prepared from HeLa cells transfected with empty vector or plasmids expressing the indicated rabbit $\beta$-globin constructs. After agarose gel electrophoresis and UV crosslinking, $28 \mathrm{~S}$ ribosomal RNA was detected by staining the membrane with methylene blue. $\beta$-Globin RNA was detected by hybridization to a $\beta$-globin RNA-specific antisense oligonucleotide.

2015). As expected, no RNA-PLA signal was detected in cells incubated with anti-Drosha antibody, even though the Drosha RNA processing enzyme, which does not process the HVS pri-miRNA, is highly abundant in the nucleus.

Compared to other PLA-based methods that detect RNAprotein interactions (Lifland et al. 2011; Jung et al. 2013b), our protocol is simple, inexpensive, time-efficient, uses commercially available reagents, and requires minimal cell manipulation and no insertion of foreign sequences into the RNA. In most cases, we designed active RNA-PLA oligonucleotide probes by using a simple on-line prediction tool, but it is also possible to experimentally map accessible sites on RNA. Upon addition of DNA oligonucleotides to cell lysates, DNA-RNA hybrids form at accessible sites, resulting in cleavage at those sites by endogenous RNase $\mathrm{H}$, which can be detected by Northern blot analysis (Lee et al. 2015). This approach was used to identify the EBER2 probe. However, we have not systematically studied the impact of oligonucleotide probe position within the target RNA. Such studies are likely to provide additional guidance regarding probe design.

RNA-PLA should be valuable to confirm that RNA-protein interactions initially detected by biochemical approaches do, in fact, occur in cells. Because the oligonucleotide probes that anneal to the target RNAs are delivered to cells after membrane permeabilization and fixation, we are able to detect RNA-protein complexes in specific intracellular compartments. Thus, RNA-PLA may be especially useful for exploring RNA-protein interactions that are induced or occur in different intracellular locations under certain physiological conditions or in response to various treatments. In addition, it may be possible to combine RNA-PLA with standard immunofluorescence staining of differentiated cell markers to allow the detection of RNA-protein complexes in specific cell types in heterogeneous cell populations or tissues. Finally, although we have used RNA-PLA to detect and analyze known RNA-protein interactions, it may also be possible to use this approach to identify novel RNA-protein interactions. For example, to detect RNAs that are bound by a specific RNA binding protein, a panel of RNA-PLA oligonucleotide probes that hybridize to different candidate target RNAs could be tested individually for their ability to generate a PLA signal with an antibody probe that recognizes the protein of interest. However, because of the complex, folded structure of many RNAs, we do not believe RNA-PLA can be used to assess the distance between the oligonucleotide binding site in the RNA and the bound protein.

We can also envision a number of modifications of RNAPLA that will make it suitable for additional applications. A previous publication successfully detected c-Myc/Max/RNA polymerase II interactions by modified protein PLA, in 
which three pairs of primary antibodies/proximity probes conjugated with short DNA oligonucleotides recognize each of the three proteins in a complex (Soderberg et al. 2006). Similarly, it may be possible to use an RNA-PLA strategy to detect the coexistence of two proteins bound to an RNA molecule. It may also be possible to modify the technique to detect specific RNA-RNA interactions or DNAprotein interactions in intact cells.

\section{MATERIALS AND METHODS}

\section{Cell culture}

HEK293T and HeLa cells were maintained in Dulbecco's modified Eagle's medium (DMEM) supplemented with 10\% (v/v) fetal bovine serum (FBS), 1\% (v/v) penicillin-streptomycin, and $2 \mathrm{mM} \mathrm{L}-$ glutamine. BJAB and BJAB-B1 cells (Fresen and zur Hausen 1976) were maintained in RPMI medium containing the same supplements. $10^{5}$ cells were plated on $12 \mathrm{~mm}$ glass coverslips in a 24 well plate and incubated at $37^{\circ} \mathrm{C}$ overnight. To improve adhesion of $293 \mathrm{~T}$ cells, coverslips were coated with poly-L-lysine according to manufacturer's instructions (Sigma-Aldrich). In experiments in Figures 3 and 4, cells were treated as indicated with $5 \mu \mathrm{g} / \mathrm{mL}$ actinomycin D (Sigma-Aldrich) or $0.25 \%$ DMSO vehicle control for $1 \mathrm{~h}$ at $37^{\circ} \mathrm{C}$ prior to RNA-PLA.

\section{RNA-PLA probe design}

The RNA-PLA probes targeting the RNA of interest are ultramer DNA oligonucleotides purchased from IDT DNA Technologies. A typical PLA probe consists of three regions from $5^{\prime}$ to $3^{\prime}:(A)$ a 40-50 nucleotide (nt) sequence complementary to (or sense to) the RNA of interest. This sequence was designed based on RNA FISH probes in the literature or targeted an unstructured region as determined by RNase $\mathrm{H}$ assays; $(B)$ 20-35 adenylates that serve as a linker; and $(C)$ a 25 -nt sequence that bridges the DNA circle and serves as a primer for rolling-circle amplification during PLA detection (Soderberg et al. 2006). Regions B and C are identical for all probes. We suggest using online FISH probe design resources (e.g., http://prober.cshl.edu/) to identify region A for each target RNA. The sequences of all oligonucleotides used in this study are shown in Supplemental Table S1.

\section{Fixation, permeabilization, and blocking for PLA}

Cells were washed once with phosphate-buffered saline (PBS) and fixed in $4 \%$ formaldehyde $(\mathrm{v} / \mathrm{v})$ in PBS on ice for $30 \mathrm{~min}$. The samples were permeabilized with $1 \%$ saponin (w/v) (Sigma-Aldrich) for $1 \mathrm{~h}$ at room temperature and washed three times with PBS. The samples were then blocked with blocking buffer (10 mM Tris-acetate, $\mathrm{pH} 7.5,10 \mathrm{mM}$ magnesium acetate, $50 \mathrm{mM}$ potassium acetate, $250 \mathrm{mM} \mathrm{NaCl}, 0.25 \mu \mathrm{g} / \mu \mathrm{L}$ bovine serum albumin [BSA], and $0.05 \%$ Tween 20) in the presence of $20 \mu \mathrm{g} / \mathrm{mL}$ sheared salmon sperm DNA (sssDNA) at $4^{\circ} \mathrm{C}$ for $1 \mathrm{~h}$. One hundred nanomolar specific oligonucleotide probe was added to fresh blocking buffer, heated at $70^{\circ} \mathrm{C}$ for $3 \mathrm{~min}$, and incubated with fixed/permeabilized cells at $37^{\circ} \mathrm{C}$ for another hour or at $4^{\circ} \mathrm{C}$ overnight. Subsequently, the cells were washed three times with PBS and blocked in PBS with Tween 20 (PBST [137 mM NaCl, $2.7 \mathrm{mM} \mathrm{KCl,} 10 \mathrm{mM} \mathrm{Na}_{2} \mathrm{HPO}_{4}$,
$1.8 \mathrm{mM} \mathrm{KH}_{2} \mathrm{PO}_{4}$, and $0.1 \%$ Tween-20]) containing $1 \%(\mathrm{v} / \mathrm{v}) \mathrm{BSA}$ and $20 \mu \mathrm{g} / \mathrm{mL}$ sssDNA at room temperature for $1 \mathrm{~h}$.

\section{Primary antibody, RNA probes, and PLA probes}

The samples were washed once with PBS, once with $300 \mathrm{mM} \mathrm{NaCl}$, $30 \mathrm{mM}$ sodium citrate buffer, $\mathrm{pH} 7.0(2 \times \mathrm{SSC})$ containing $0.1 \%(\mathrm{v} / \mathrm{v})$ Tween 20, once with PBS, and incubated with the appropriate primary antibody in PBST at room temperature for $1 \mathrm{~h}$. The source of antibodies and dilutions are shown in Supplemental Table S2. The probe solution was prepared by diluting the corresponding species-specific minus PLA probe (Olink Bioscience) 1:5 into PBST containing $20 \mathrm{mg} / \mathrm{mL}$ sssDNA and allowing the mixture to sit for $20 \mathrm{~min}$ at room temperature. After three washes with PBS, the coverslips were transferred to a prewarmed humidified chamber (Lipovsky et al. 2015) and incubated with the probe solution for $1 \mathrm{~h}$ at $37^{\circ} \mathrm{C}$.

\section{Ligation, amplification, and labeling}

The subsequent PLA ligation and amplification steps were performed according to the manufacturer's instructions (Olink Bioscience). Briefly, the PLA probe solution was aspirated from the cells and samples were washed twice with wash buffer A for 5 min each under gentle agitation. Cells were incubated with freshly prepared ligation mix for $30 \mathrm{~min}$ at $37^{\circ} \mathrm{C}$. Samples were then washed twice with wash buffer A for 2 min each with gentle agitation and incubated with freshly prepared amplification mix for $100 \mathrm{~min}$ at $37^{\circ} \mathrm{C}$. To enhance the signal intensity, the amplification step can be extended to $2-4 \mathrm{~h}$ if needed. Cells were washed twice with wash buffer B for $10 \mathrm{~min}$ with gentle agitation and stained with 4',6-diamidino-2-phenylindole (DAPI). After a final wash with $0.01 \times$ wash buffer B for $1 \mathrm{~min}$, samples were mounted onto glass slides with FluorSave reagent (EMD Millipore).

\section{Microscopy and image analysis}

Images were captured by Leica TCS SP5 fluorescent microsystems using appropriate filters. All images were taken with the same exposure time and the same threshold to allow subsequent quantitative analysis in the respective channel. At least 150 nuclei per sample were imaged and the images were processed with ImageJ. Statistical analyses were then done by Blobfinder software (available for download from the Centre of Image Analysis at Uppsala University, http://www.cb.uu.se/ amin/BlobFinder) to determine the total fluorescence intensity per cell (Lipovsky et al. 2015). Experiments were repeated three times and averaged to obtain mean \pm SEM. There is a low, variable background in these experiments, which is typically $<10 \%$ of the signal deemed positive.

\section{Fluorescence in situ hybridization}

Cells were fixed, permeabilized, and blocked as described for the PLA assays. The samples were hybridized overnight at $37^{\circ} \mathrm{C}$ with $50 \mathrm{nM}$ digoxygenin (DIG)-labeled oligonucleotide probes that recognize sequences in the $3^{\prime}$ UTR of $\beta$-actin mRNA (see Supplemental Table S1). Sense and antisense oligonucleotides (purchased from IDT DNA Technologies) were labeled with DIG-dUTP using the 3' DIG Oligonucleotide Tailing kit, 2nd generation (Roche), 
according to the manufacturer's instructions. After hybridization, slides were washed twice for $10 \mathrm{~min}$ each in $2 \times \mathrm{SSC}$ at $37^{\circ} \mathrm{C}$ followed by two 10 -min washes in $1 \times \mathrm{SSC}$ at $37^{\circ} \mathrm{C}$ and a final wash with $0.5 \times$ SSC for $10 \mathrm{~min}$ at room temperature. Cells were fixed again in $4 \%$ formaldehyde/PBS and washed three times in PBS; hybridized probes were detected using a 1:250 dilution of anti-DIG antibody conjugated to fluorescein (green; Roche) in blocking buffer at room temperature for $1 \mathrm{~h}$.

\section{Immunofluorescence}

HeLa cells grown on glass coverslips were treated with $5 \mu \mathrm{g} / \mathrm{mL}$ ActD or vehicle control for $1 \mathrm{~h}$, fixed with $4 \%$ paraformaldehyde in PBS, and permeabilized with $1 \%$ saponin in PBS. After incubation in blocking buffer (DMEM containing 10\% FBS) for $1 \mathrm{~h}$ at room temperature, samples were stained with a 1:1000 dilution of anti-HuR mouse antibody followed by incubation with 1:200 dilution of the AlexaFluor 488 goat anti-mouse antibody (Molecular Probes). Both antibodies were diluted in blocking buffer. The nuclei were stained with DAPI (blue). The images were taken by Leica TCS SP5 fluorescent microsystems and processed with ImageJ.

\section{Plasmids, transfection, and Northern blotting}

Plasmids described elsewhere express rabbit $\beta$-globin mRNA ( $\mathrm{pBBB})$ or the same mRNA with a $\mathrm{c}$-fos or GM-CSF ARE inserted into the $\beta$-globin mRNA 3' UTR (Fan et al. 1997). HeLa (JW36) cells in six-well plates were transfected with $0.5 \mu \mathrm{g}$ of pBBB plus $1.5 \mu \mathrm{g}$ pBluescript or with $2 \mu \mathrm{g}$ of pB-ARE (c-fos) or pB-ARE (GM-CSF) containing an inserted ARE. Lipofectamine 2000 (Invitrogen) was used for transfection according to the manufacturers' instructions. Twenty-four hours later, $10^{5}$ transfected cells were seeded on glass coverslips in a 24-well plate for another $24 \mathrm{~h}$. The cells were treated with $5 \mu \mathrm{g} / \mathrm{mL}$ ActD for $1 \mathrm{~h}$, fixed, and processed for PLA. Alternatively, after $72 \mathrm{~h}$, total RNA was harvested using TRIzol reagent (Invitrogen), and $25 \mu \mathrm{g}$ total RNA was resolved in a $1.4 \%$ agarose $(\mathrm{w} / \mathrm{v}) / 6.5 \%$ formaldehyde $(\mathrm{v} / \mathrm{v})$ gel and transferred to a ZetaProbe GT blotting membrane (Bio-Rad) via upward capillary transfer with $20 \times$ SSC. The membrane was crosslinked with $254 \mathrm{~nm} \mathrm{UV}$ light at $120 \mathrm{mj} / \mathrm{cm}^{2}$ using Stratalinker UV crosslinker 2400 (Agilent genomics). To detect $28 \mathrm{~S}$ rRNA, the membrane was stained with $0.3 \%$ methylene blue $(\mathrm{v} / \mathrm{v})$ in $0.3 \mathrm{M}$ sodium acetate, $\mathrm{pH} 5.2$, for 2-3 min until the $28 \mathrm{~S}$ rRNA bands were clearly visible. Images were taken with the Gel Doc system. Fifty picomoles of rabbit $\beta$-globin DNA oligonucleotide probe was $5^{\prime}-\left[{ }^{32} \mathrm{P}\right]$ labeled and hybridized in $10 \mathrm{~mL}$ of ExpressHyb Hybridization Solution (Clonetech) at $42^{\circ} \mathrm{C}$ overnight. The membrane was washed with $1 \times$ SSC, $0.1 \%$ SDS (20 min at room temperature), $0.5 \times$ SSC, $0.1 \%$ SDS (20 min at room temperature) and analyzed by PhosphoImager.

\section{SUPPLEMENTAL MATERIAL}

Supplemental material is available for this article.

\section{ACKNOWLEDGMENTS}

The authors thank members of the Steitz and DiMaio laboratories for critical discussion and technical suggestions, and J. Zulkeski for assistance in preparing this manuscript. This work was supported by the National Institutes of Health (P01 CA016038 to D.D. and J.A.S.; R01 AI102876 to D.D.; R01 CA193300 to J.A.S.; K99 CA190886 to M.X.) and the Ruth L. Kirschstein National Research Service Award (F32AI114132 to W.Z.). J.A.S. is an investigator of the Howard Hughes Medical Institute.

Received July 7, 2016; accepted August 25, 2016.

\section{REFERENCES}

Condeelis J, Singer RH. 2005. How and why does $\beta$-actin mRNA target? Biol Cell 97: 97-110.

Dai W, Zhang G, Makeyev EV. 2012. RNA-binding protein HuR autoregulates its expression by promoting alternative polyadenylation site usage. Nucleic Acids Res 40: 787-800.

Darnell RB. 1996. Onconeural antigens and the paraneoplastic neurologic disorders: at the intersection of cancer, immunity, and the brain. Proc Natl Acad Sci 93: 4529-4536.

Dormoy-Raclet V, Menard I, Clair E, Kurban G, Mazroui R, Di Marco S, von Roretz C, Pause A, Gallouzi IE. 2007. The RNA-binding protein HuR promotes cell migration and cell invasion by stabilizing the $\beta$ actin mRNA in a U-rich-element-dependent manner. Mol Cell Biol 27: 5365-5380.

Fan XC, Myer VE, Steitz JA. 1997. AU-rich elements target small nuclear RNAs as well as mRNAs for rapid degradation. Genes Dev 11: 2557-2568.

Fok V, Friend K, Steitz JA. 2006. Epstein-Barr virus noncoding RNAs are confined to the nucleus, whereas their partner, the human La protein, undergoes nucleocytoplasmic shuttling. J Cell Biol 173: 319-325.

Fresen KO, zur Hausen H. 1976. Establishment of EBNA-expressing cell lines by infection of Epstein-Barr virus (EBV)-genome-negative human lymphoma cells with different EBV strains. Int J Cancer 17: 161-166.

Gallouzi IE, Brennan CM, Stenberg MG, Swanson MS, Eversole A, Maizels N, Steitz JA. 2000. HuR binding to cytoplasmic mRNA is perturbed by heat shock. Proc Natl Acad Sci 97: 3073-3078.

Glickman JN, Howe JG, Steitz JA. 1988. Structural analyses of EBER1 and EBER2 ribonucleoprotein particles present in Epstein-Barr virus-infected cells. J Virol 62: 902-911.

Glisovic T, Bachorik JL, Yong J, Dreyfuss G. 2008. RNA-binding proteins and post-transcriptional gene regulation. FEBS Lett 582: 1977-1986.

Hesketh JE, Pryme IF. 1991. Interaction between mRNA, ribosomes and the cytoskeleton. Biochem J 277 (Pt 1): 1-10.

Jung J, Lifland AW, Alonas EJ, Zurla C, Santangelo PJ. 2013a. Characterization of mRNA-cytoskeleton interactions in situ using FMTRIP and proximity ligation. PLoS One 8: e74598.

Jung J, Lifland AW, Zurla C, Alonas EJ, Santangelo PJ. 2013b. Quantifying RNA-protein interactions in situ using modifiedMTRIPs and proximity ligation. Nucleic Acids Res 41: e12.

Lee N, Moss WN, Yario TA, Steitz JA. 2015. EBV noncoding RNA binds nascent RNA to drive host PAX5 to viral DNA. Cell 160: 607-618.

Lerner MR, Andrews NC, Miller G, Steitz JA. 1981. Two small RNAs encoded by Epstein-Barr virus and complexed with protein are precipitated by antibodies from patients with systemic lupus erythematosus. Proc Natl Acad Sci 78: 805-809.

Lifland AW, Zurla C, Yu J, Santangelo PJ. 2011. Dynamics of native $\beta$ actin mRNA transport in the cytoplasm. Traffic 12: 1000-1011.

Lipovsky A, Zhang W, Iwasaki A, DiMaio D. 2015. Application of the proximity-dependent assay and fluorescence imaging approaches to study viral entry pathways. Methods Mol Biol 1270: 437-451.

Lopez de Silanes I, Zhan M, Lal A, Yang X, Gorospe M. 2004. Identification of a target RNA motif for RNA-binding protein HuR. Proc Natl Acad Sci 101: 2987-2992. 
Lunde BM, Moore C, Varani G. 2007. RNA-binding proteins: Modular design for efficient function. Nat Rev Mol Cell Biol 8: 479-490.

Moss WN, Lee N, Pimienta G, Steitz JA. 2014. RNA families in EpsteinBarr virus. RNA Biol 11: 10-17.

Paige JS, Wu KY, Jaffrey SR. 2011. RNA mimics of green fluorescent protein. Science 333: 642-646.

Raj A, van den Bogaard P, Rifkin SA, van Oudenaarden A, Tyagi S. 2008. Imaging individual mRNA molecules using multiple singly labeled probes. Nat Methods 5: 877-879.

Seraphin B. 1995. Sm and Sm-like proteins belong to a large family: identification of proteins of the U6 as well as the U1, U2, U4 and U5 snRNPs. EMBO J 14: 2089-2098.

Soderberg O, Gullberg M, Jarvius M, Ridderstrale K, Leuchowius KJ, Jarvius J, Wester K, Hydbring P, Bahram F, Larsson LG, et al. 2006. Direct observation of individual endogenous protein complexes in situ by proximity ligation. Nat Methods 3: 995-1000.
Strack RL, Jaffrey SR. 2015. Live-cell imaging of mammalian RNAs with Spinach2. Methods Enzymol 550: 129-146.

Weibrecht I, Lundin E, Kiflemariam S, Mignardi M, Grundberg I, Larsson C, Koos B, Nilsson M, Soderberg O. 2013. In situ detection of individual mRNA molecules and protein complexes or posttranslational modifications using padlock probes combined with the in situ proximity ligation assay. Nat Protoc 8: 355-372.

Wolin SL, Cedervall T. 2002. The La protein. Annu Rev Biochem 71: 375-403.

Xie M, Zhang W, Shu MD, Xu A, Lenis DA, DiMaio D, Steitz JA. 2015. The host integrator complex acts in transcription-independent maturation of herpesvirus microRNA 3' ends. Genes Dev 29: 1552-1564.

Zurla C, Jung J, Santangelo PJ. 2016. Can we observe changes in mRNA "state"? Overview of methods to study mRNA interactions with regulatory proteins relevant in cancer related processes. Analyst 141: 548-562. 

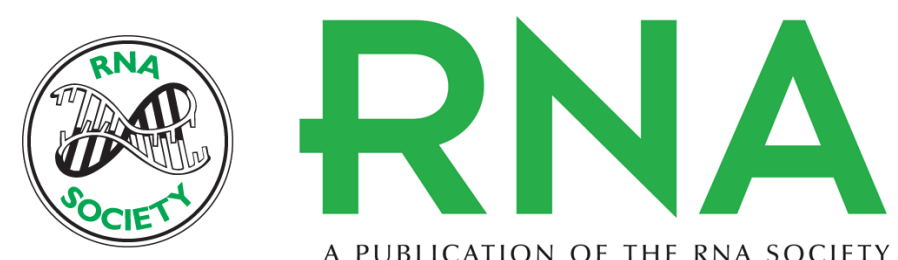

A PUBLICATION OF THE RNA SOCIETY

\section{A proximity-dependent assay for specific RNA-protein interactions in intact cells}

Wei Zhang, Mingyi Xie, Mei-Di Shu, et al.

RNA 2016 22: 1785-1792 originally published online September 22, 2016

Access the most recent version at doi:10.1261/rna.058248.116

\section{Supplemental http://rnajournal.cshlp.org/content/suppl/2016/09/22/rna.058248.116.DC1 Material}

References This article cites 29 articles, 11 of which can be accessed free at: http://rnajournal.cshlp.org/content/22/11/1785.full.html\#ref-list-1

Creative This article is distributed exclusively by the RNA Society for the first 12 months after the Commons License full-issue publication date (see http://rnajournal.cshlp.org/site/misc/terms.xhtml). After 12 months, it is available under a Creative Commons License (Attribution-NonCommercial 4.0 International), as described at http://creativecommons.org/licenses/by-nc/4.0/.

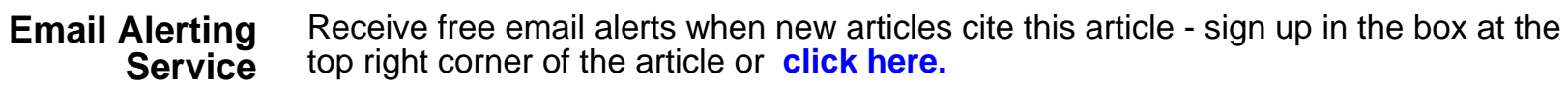

